\title{
A study on Chinese international students' social life in American Universities
}

\author{
Hanning Ma \\ Grade 12, Shanghai Guanghua Cambridge International School, Zhengxi Road, Shanghai, China
} aubreyma0912@gmail.com

Keywords: Cross-cultural, identity, socio-cultural adjustment

\begin{abstract}
Based on the personal experience of upperclassman and previous research, it is common for Chinese students studying abroad to build their own social circle. Most students lack interactions with people from western countries. The following paper a study was conducted to further investigate the reasons for this phenomenon and Chinese students' attitude towards this situation. Five interviews and ninety-eight surveys were distributed to Chinese students who are studying in United States. The results reveal that a large proportion of them hold the point that making friends depends on various factors, not only their nationalities. We can use this knowledge to help students who attempt to study in a foreign environment adapt to the new setting quickly and adjust their mental conditions better.
\end{abstract}

\section{Introduction}

Humans crave similarity. We feel better if we spend time with people who are like us in ways that are important for our own identities. One finds a clear example of this phenomenon in the case of students who are studying abroad. Students who study abroad tend to maintain friendship networks composed of individuals who are, like them, studying abroad.

Through casual observation, including my own personal observations of friends' posts on social media, I saw that Chinese students studying abroad tended to socialize exclusively with other Asian students, mostly Chinese students. Also, joining the CSSA (Chinese Students and Scholars Association) and attending related activities are common. Networks are formed and maintained both in one-on-one interactions and through involvement in formally organized exclusively Chinese student social organizations. They seem to stay in a fixed social network and had few interactions with students from western countries. In this case, developing an exclusively Chinese social circle becomes a normality among them. Personal interactions and ongoing social relationships with students who are residents of the host country are relatively rare; non-instrumental, purely informal social interactions tend to happen solely with fellow Chinese national students.

After observing so many cases of upperclassman, I am interested in finding out what forces them and other students to stay with those having similar backgrounds. Why do Chinese national students studying in the United States tend to maintain exclusively Chinese social networks? Some people argue that it is because of language barriers that force them to do that; however, I want to find other factors contributing to this phenomenon. I suspect that there are other contributing factors, such as difficulty fitting in to a foreign environment, were also important, and the literature shows that cultural difference, self-adjustment, and stereotypes held by natives of the host country are the most important factors.

Since I am in an international school, which means that my classmates and I will study abroad in the future, I thought that it would be useful to investigate a topic which will be relatable to our social life. Considering that I am in China and the time limit, I want to investigate mainly Chinese students to ensure it is feasible since I can contact my upper-class classmates who are studying abroad in the U.S. Initially, my theory was that most Chinese students will desire to blend into the native environment but that it is hard to do for several reasons. I can carry interviews through social media and use questionnaires to get information. According to the literature, the factors can be simplified to three aspects: cultural difference, self-adjustment, and native people's stereotypes. 
However, the attitudes of Chinese international students towards their social network are quite different from what I assumed. Instead, they play a surprising role as well.

\section{Literature Review}

The transition for Chinese students to American college can be a painful experience since they have to struggle with the new setting around them. It is common to hear from the Chinese international students that they always stay with Chinese people or Asians in universities. They put themselves in the "bubble" by working for their academic works and ignoring socializing with native students. Even if a part of them does not mind this and they are happy with their present social life, some of them want to change and befriend American students as one of the reasons for them to study abroad is to experience a new culture and meet more different people. These experiences may become the precious treasures of their future work or life. It is important for us to know which factors create the "bubble" so that we can help international students who want to more native friends in universities or bothered by present social life.

\subsection{Cultural Difference}

It has almost become a cliché to say that the cultural difference is important for the international students to adapt to the new environment well. Several factors could be the composition of culture. As several studies suggest that the level of English fluency is one of the obstacles for international students to communicate with native students. Since lack of English fluency can bring abundant negative effects such as being less satisfied with their community relations (Perrucci \& Hu, 1995) and finding it more difficult to make friends (Heikenheimo \& Shute, 1986), Students who had minimal language barriers can adapt at functioning in the culture and establishing the social network with American students (Trice, 2004). Also, 23\% of American students perceive international students as deficient in English language ability (Spencer-Rodgers, 2001). Spencer-Rodgers conducted a survey-based research. She gathered 100 students who were citizens or nationals of the United States to get their response about the perceptions of international students. Language deficiency is one of her findings. In addition to the language barrier, distinct lifestyle and beliefs are also indispensable reasons for international students' lack of activeness with the native community. Americans prefer to socialize with people who share common beliefs and lifestyles (Trice, 20014). This will vary from different regions around the world. Trice focuses on investigating the social patterns of international students from every world region. To conduct this research, she sent 2001 mail questionnaires and finally got 497 responds from different regions' international students. The data shows that 95\% Canadian students who have a relatively similar culture with American students interacted with them at least every other week, while only 39\% students from East Asia did the same thing. The similar culture background is advantageous during the process of establishing friendship.

\subsection{Self-adjustment}

The second area we will explore is the ability of self-adjustment. According to Harry (1989), the self may include attitudes, beliefs, intentions, norms, rules, and values. Since the new environment may contradict the self of international students, most international students may experience cultural shock early in the semester. During this process, they may feel lonely, some may even get to the point of depression (Erlenawati \& Simon \& Ana \& Chris \& Gaby, 2008). Their selves will be different from other students due to their diverse backgrounds. Thus, the ability of self-adjustment which indicates the level of adaption is indispensable for international students to blend into the new culture and socialize with the native students. To conduct the research about which factors could lead to better adaption, Ruben \& Kealey (1979) employ four adjustment indicators based on their level of comfort, acceptance, and satisfaction with several aspects of life and work; the words summarized by participants about their feeling of experiences there; the six item alienation-adjustment index (provided in Appendix, Middleton, 1963); and the in-the field observations of psychological adjustment (Harry, 1989). The result indicates that the people who 
display more respect are likely to adapt the new environment. Also, people vary their behaviors according to the desires of others. The ability of reacting to ambiguous situation with minimal discomfort is called Tolerance of Ambiguity, displays a positive relation with the level of adaption. Students who are more tolerant and regard studying abroad as an opportunity to make friends or the mean to gain potential benefits for future works are more active (Steve \& Therese, 2004). They tend to have fewer barriers in socializing with native students.

\subsection{Personalities \& Stereotype}

In addition to the culture differences and the self-adjustment ability of the international students, their personalities and the stereotype of them by native students also contributes to the situation that it is hard for international students and native students to be the close friends. For example, American students generally have the positive impression about international students since 58\% of 100 American students use the word Intelligent and 41\% uses Brave to describe the international students. However, they are also frequently characterized as individuals with "a different culture, perspectives, and beliefs" (15\% of the sample). In addition, it is common for them (15\%) to think that the international students are unsociable (Spencer-Rodgers, 2001). These stereotypes could prevent them from building up in-depth friendships. Analysis from international students' personalities, Ruben\& Kealey (1979) suggests that more self-centered behaviors would be less effective in the process of making American friends. Conversely, the tolerance of ambiguity play a positive role as mentioned before. Furthermore, international students who are concerned about the matter and cared about the social network with native students would be more active. "People who defined themselves as doers of a particular behaviors were more likely to do that behavior," stated by Harry (1989), could support the argument. 49\% of East Asian students are concerned with the establishment of American Friendship (Trice, 2004). They may attend more events, and therefore increase the exposure of the cultural activities. Through sending questionnaires to the international students in the American campus, 497 responses show that the extent that students engage in the cultural events in the universities is an important factor for making more American friends (Trice, 2004).

All in all, all of the literature that I reviewed has achieved reasonable analysis and abundant data was collected. They inform which factors could be the reason of international students' stay with the people who have similar backgrounds and they used the method which is most suitable for their researches. Some of them even give them recommendations on how to improve the skills to immerse international students in the new environment and gain more friendships with native people. However, since some of the literature was conducted in late $18^{\text {th }}$ centuries, it is possible for the international students to have changed their feeling about "staying in the bubble." Also, all the literature I reviewed talks about the international students as a whole group, but not all the results can be applied to my target group, the Chinese international students. In addition, many of them pay less attention to analyze which type of friends that international students prefer to make and only the difficulties that they may encounter. My research may analyze the relationships between Chinese international students and American students from their own perspectives.

\section{Method}

My research methods included surveys and in-depth interviews. These two methods were chosen because of their ability to address both a broader range of student experiences and students' personal understandings of their experiences. Surveys are an efficient way to gather information quickly from a large number of respondents. Because of our physical distance-I am in China but my interview subjects are, necessarily, currently students in the United States-surveys were conducted using an online program, "Website for Questionnaires." 98 respondents completed the survey. Because of the limitations of surveys, such as the more general tone of questions, and the necessity for subjects to choose from a limited number of responses, in-depth interviews provided several of my subjects with a crucial opportunity to elaborate on their responses, giving additional detail in conversation with me. Surveys asked for basic information, such as the length of the 
subject's stay in the United States, as well as inquiring about various aspects of their social lives, including the predominant ethnicity of their friends, what activities they shared in common, how they contacted each other, and the extent to which they were interested in expanding their social groups to include more non-Chinese students. My survey and interview questions are included in an appendix at the end of this paper.

My second method is in-depth interviews which enabled me to get insights of the topic. I also use the snowball sampling method to contact four Chinese students who are studying in the American universities. We used the WeChat's voice call to do the interview. The questions of my interview contain some introductory questions. For example, "which ethnic groups is the largest proportion of your social network at the university?" Setting these questions can help us to be more familiar in a short period so that it will be easier for the sample population to express their opinions in front of me. Also, the interview consisted some open question in order to get a more detailed, in-depth, and personal answers. All of my interviews were about 15 minutes each. Two male and two female students were interviewed.

\section{Finding \& Discussions}

\subsection{Relevant Factors Influencing Their Social Life}

The following Figures and selected quotes from interviews show the factors that may influence the social life of Chinese students studying in the American universities.

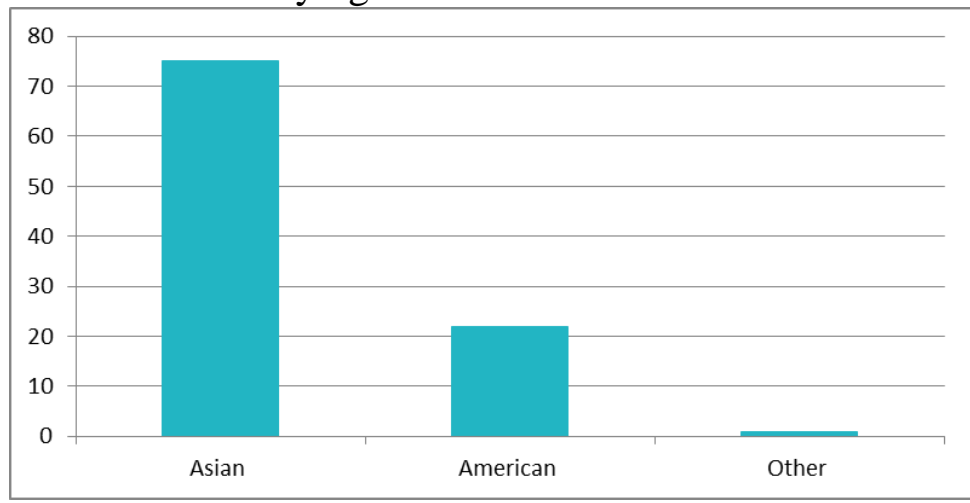

Figure 1 Which ethnic group is the largest proportion of your social network in the university?

Figure 1 shows the results of "Which ethnic group is the largest proportion of your social network in the university?” 76.53\% of the sample population chose Asian students. Also, 22 of 98 persons chose that most of their friends are Chinese people. In addition, three of four interviewees' friends are Chinese students. These support our assumption that most international students stay with Chinese students or people who have similar backgrounds.

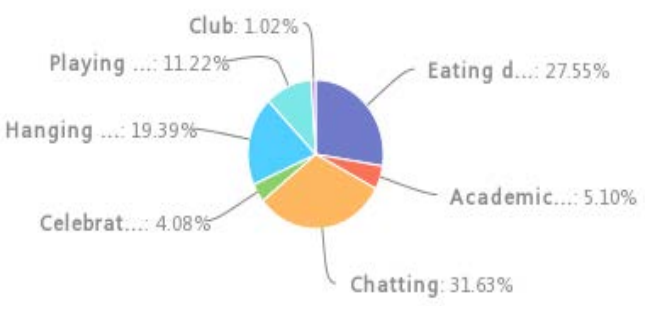

Figure 2

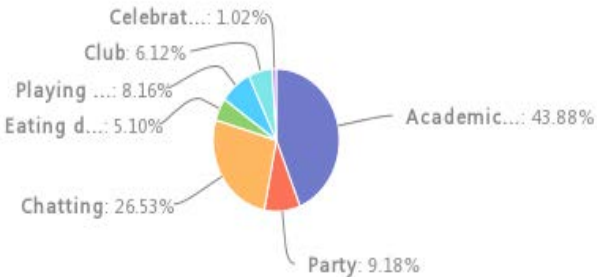

Figure 3

The questionnaires also include a question about what the common activities when they stay with Chinese friends and American students are. Figure 2 displays that when they stay with the Chinese students, they always chat with each other or eat dinner. However, according to Figure 3, for American students, the most common activity is doing academic projects. It is obvious that the activities they do with Chinese students are more personal and relaxing than the activities they do 
with others. The possible reasons for this result can be concluded from the response from the interviews. One interesting finding is that according to the survey responses, only a few people will meet foreign students in club activities. However, this contradicts the results from interviewees. Subject 1 always meet foreign students in dancing club; Subject 2 always attend the activities in school's newspaper office; and Subject 3 usually has contact with foreign students in sport clubs.

Quote 1:

"Even if we pass a lot of standardized language test, it is not enough. If you want to communicate with them without any problems, you have to spend several years. Actually, they will not say many slang or idioms when they talk to international students. Also, if you do not understand some words, you can ask them directly because they will not mind this. " (Subject 3)

This quote shows the most common factor, language barriers, preventing international students to have deep conversations with American students. But it also points out that American students will not say something too local when they talk with international students. This indicates that native students have an impression of "foreigners" assume they lack English fluency. This stereotype could be one of the factors which can be supported by the literature review.

Quote 2:

"You cannot join the conversation of Americans sometimes. You know, you cannot get their laugh point... For instance, when I am in the newspaper office, one of my American friend, an editor, she asked: who know about some local newspaper?' Actually I do not read newspaper every day so I say Shanghai Daily hah. Others may say Philadelphia Independent and talk balabalabala... At this time, I cannot join their conversation. I know nothing which is very 'local'. And they like talking about politics or relevant events." (Subject 2)

The example mentioned by quote 2 shows the different elements of culture, including the local political affairs. Few international students read the American local newspapers. This leads to a failure of information, which can then create gap in the conversation of the Chinese and American students. Also, subject 1 and 2 mentioned that there is an eating habit difference between them. As Chinese students prefer going outside the campus and eat Chinese food, American student are used to eating pizza, sandwich or invite friends to the dormitory to cook. Both of these difference can be attributed to the different environments we grow up in.
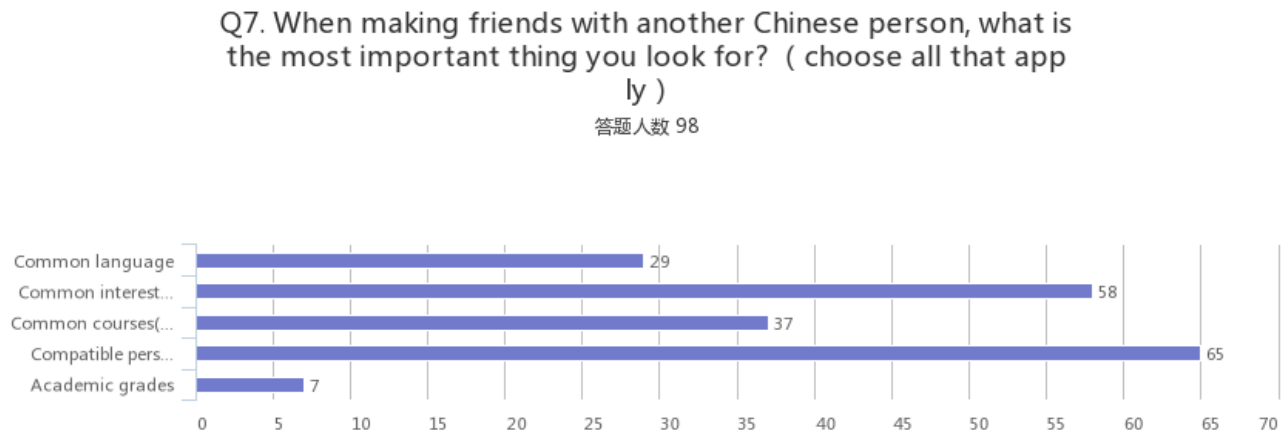

Figure 4

In addition to language barrier and culture, one of the most important factors suggested by interviewees and the quantitative data is their personalities and their values rather their nationalities. Figure 4 reveals that 68 of the 98 sample population would be more willing to make friends with people who have compatible personalities. The specific characteristics or personalities could be "friendly" (indicated by quote 3), "sincere”, and “caring” (indicated by quote 4).

Quote 3:

“He/she should be friendly. I will identify whether or not our values are compatible.” (Subject 4)

Quote 4:

"He will express his opinions directly. For example, in my social circle, my friends who I always stay with are really caring. For instance, our tradition is if today is his or her birthday...ah, there is one of my friend's birthday is precisely today, others in our circle will prepare a gift for him/her and lead him to a mysterious place to give him/her a surprise. I think it is really funny. Maybe we will be 
busy, but we will still empty one or two hours to celebrate his/her birthday together.” (Subject 2)

The final factor beyond my expectation but mentioned by two interviewees is the socioeconomic status. Quote 5 and quote 6 describe their own experiences on campus. As some super rich students have more luxurious lifestyles and someone may judge other students by that brand they wear, they cannot join the same type of activities or the common conversation topics. Also, both interviewees feel uncomfortable about the judgment of rich students. The unmatched value becomes the obstacle of the relation. However, when I ask Subject 3 about whether the family income will divide the social network, he says he did not perceive this kind of phenomenon. As this factor was not accounted by me before designing the questionnaire, there is no quantitative data to support this point.

Quote 5:

"For instance, in our school, there are many rich Chinese students who will get thousands of dollars per month. Compared to them, I and ordinary students just get hundreds of dollars per month. Obviously, it is hard to get into their social circle...our lifestyle is different and sometimes we do not have something common to talk about." (Subject 4)

Quote 6:

"Many Chinese students in our school is very rich, they always judge others by which brand of clothes they wear. What is more serious is that I have a part-time job in our school's dining hall, sometimes they will pretend that they do not know you and also will not greet you. It makes me uncomfortable. Compared to them, my friends from dancing club are so caring since I always chat with them. This is not about nationalities but the personalities."(Subject 1)

\subsection{The Attitude of Changing the Social Life}

According to the survey responses, showing in Figure 5, nearly half of the people would like to make more American friends, and also about half of them like their present social network. This means a large proportion of Chinese international students will not be worried about the "bubble" and they are satisfied by the present social life.

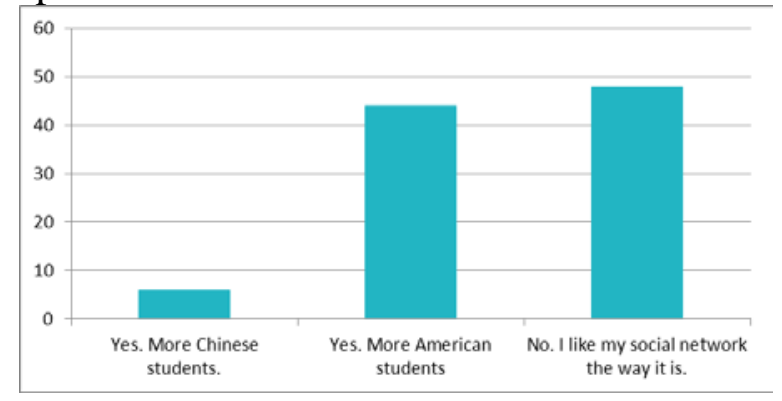

Figure 5

Quotes 7:

"Sure... Um... Maybe. Well, I think in American universities, the Chinese social circle is very broad actually. Some Chinese students will not make friends with Americans intentionally. Making friends is a (pause) flexible thing. If your roommate is American, Spanish, or others, you may become friends. I will not to say that 'oh, I want make an American friend!' It is flexible." (Subject 2)

But the responses of interviews show a little complex idea. Just like the Quote 7 shows, they do not want to make native friends intentionally. All of them have the interest in making more American friends. The reasons are experiencing the American culture further or enhancing the potential work opportunities in the future. Meanwhile, all of them are satisfied by their present situation since they hold the point that making friends is quite flexible. They prefer people who can influence themselves positively or compatible personalities.

\section{Ethics}

Before conducting the interview, I informed the interviewees that I would record the interview 
content and that it would take about 30 minutes. Also, I introduced my research quickly before asking questions. No real names were used on this paper in order to maintain interviews' privacy.

\section{Conclusions}

The initial purpose of the research was to help Chinese students identify which factors they could improve on in order to blend into the American society better. However, the results show that a large proportion of students now are not really concerned about this question. They feel comfortable when they stay with people who have the compatible personalities and matched values. Many of them do not really care about the nationalities and most of the time it depends on the group you are in such as dormitory, club, and class.

Thus, for people who want to make more American students, they should overcome the barrier of cultural differences and language. All of these factors nearly parallel to the literature that I found, except some factors like family income and eating habits are seldom appear in the literature. However, since most American students also characterize international students as "foreign," they will not use colloquial language. The most important is the courage to communicate with them more frequently. This could be supported by the responses from the interviews. Also, attending club activities may be a good way to meet more American students.

For student do not want to make American friends intentionally, the personalities and values are more important. It is necessary to identify what you like and which people you want to make friends with. There is no need to have too much pressure concerned about how to make friends with them. Making friends is a flexible thing that may depend on which dormitory you are in, which course you choose, and which club you join. Having a clear of view of self-identity could help international students have a casual social life.

Overall, Chinese students do construct their own fixed social network but it is not only determined by their nationalities. The point of values and personalities are more important than language when they make friends.

\section{References}

[1] Anderson, L. E. (1994). A new look at an old construct: Cross-cultural adaptation. International Journal of Intercultural Relations, 18(3), 293-328. doi:10.1016/0147-1767(94)90035-3

[2] Trice, A. G. (2004). Mixing It Up: International Graduate Students Social Interactions With American Students. Journal of College Student Development, 45(6), 671-687. doi:10.1353/csd.2004.0074

[3] Ruben, B. D., \& Kealey, D. J. (1979). Behavioral assessment of communication competency and the prediction of cross-cultural adaptation. International Journal of Intercultural Relations, 3(1), 15-47. doi:10.1016/0147-1767(79)90045-2

[4] Spencer-Rodgers, J. (2001). Consensual and individual stereotypic beliefs about international students among American host nationals. International Journal of Intercultural Relations, 25(6), 639-657. doi:10.1016/s0147-1767(01)00029-3

[5] Triandis, H. C. (1989). The self and social behavior in differing cultural contexts. Psychological Review, 96(3), 506-520. doi:10.1037//0033-295x.96.3.506

[6] Perrucci, R., \& Hu, H. (1995). Satisfaction with social and educational experiences among international graduate students. Research in Higher Education, 36(4), 491-508. doi:10.1007/bf02207908

[7] Heikenheimo, P. S., \& Shute, J. C. M. (1986). The adaptation of foreign students: Student views and institutional implications. Journal of College Student Personnel, 27, 399-406. 


\section{Appendix}

This is a questionnaire about the social life of Chinese international students studying in the U.S. Thanks for offering several minutes to answer this questionnaire!

1. Q1. How long have you been studying in USA?

$\circ 1$ year

○ 2 years

$\circ$ More than 2 years

2. Q2. Which ethnic group is the largest proportion of your social network in the university?

$\circ$ Asian

- American

$\circ$ Other

3. Q3. Most of my friends at the university are

$\circ$ Chinese

○ Not Chinese

4. Q4. I usually contact my friends

o online through social media (WeChat, Facebook, SnapChat, Instagram)

o Text message

o Online via email

o Phone

$\circ$ In person

$\circ$ Other

5. Q5. What is the most common/typical activity that you do with your Chinese social network?

$\circ$ Eating dinner

$\circ$ Academic project

$\circ$ Chatting

o Celebrating festivals

$\circ$ Hanging out in weekends

○ Playing games (board games; video games...)

- Club

6. Q6. What is the most common/typical activity that you do with your non-Chinese social network?

$\circ$ Academic projects

$\circ$ Party

$\circ$ Chatting

$\circ$ Eating dinner

○ Playing games (board games; video games...)

$\circ$ Club

- Celebrating festivals

7. Q7. When making friends with another Chinese person, what is the most important thing you look for? (choose all that apply)

$\square$ Common language

$\square$ Common interests

$\square$ Common courses(majors; minors; electives)

$\square$ Compatible personality

$\square$ Academic grades

8. Q8.If it were possible, would you like to change your current social network?

○ Yes. More Chinese students.

- Yes. More American students

$\circ$ No. I like my social network the way it is. 